\title{
Positive affect as informational feedback in goal pursuit
}

\author{
Edward Orehek $\cdot$ Elena Bessarabova $\cdot$ \\ Xiaoyan Chen • Arie W. Kruglanski
}

Published online: 17 February 2011

(C) The Author(s) 2011. This article is published with open access at Springerlink.com

\begin{abstract}
Two studies investigated the cognitive activation of a goal following a promise to complete it. Current theorizing about the impact of positive affect as informational feedback in goal pursuit suggests two contradictory conclusions: (1) positive affect can signal that sufficient progress towards a goal has been made, but also (2) positive affect can signal that commitment to a goal should be maintained. When individuals infer that significant progress toward goal achievement has been made, the goal should be deactivated, but when individuals infer that commitment to the goal should be maintained, goal activation should be increased. To determine the conditions in which positive affect leads to increased goal activation as opposed to goal deactivation, we proposed that competing goals serve as a moderator. We found that positive affect led to decreased goal activation when competing goals were present, but to increased goal activation when competing goals were absent.
\end{abstract}

Keywords Positive affect · Goals · Motivation ·

Feedback · Resources · Promises

\footnotetext{
E. Orehek $(\square)$

Department of Social and Organizational Psychology,

University of Groningen, Grote Kruisstraat 2/1,

9712 TS Groningen, The Netherlands

e-mail: e.orehek@rug.nl

E. Bessarabova

University of Oklahoma, Norman, OK, USA

X. Chen · A. W. Kruglanski

University of Maryland, College Park, MD, USA
}

\section{Introduction}

Goals are conceptualized as stored knowledge structures that can vary in their activation level at a given moment (Bargh 1990; Kruglanski 1996a). When goals are being pursued, they remain cognitively activated. However, when a goal has been attained or when sufficient progress has been made, the information associated with it is deactivated or inhibited (Forster et al. 2005; Marsh et al. 1998; Zeigarnik 1927).

Once a goal has been adopted and its pursuit has been initiated, the actor monitors the progress that has been made toward the goal (Atkinson and Raynor 1978; Carver and Scheier 1998; Feather 1990; Gollwitzer 1999; Locke and Latham 1990). Many types of information may serve as feedback on the status of goal-directed action, including thoughts about the goal (Fishbach and Dhar 2006; Oettingen and Mayer 2002), affect associated with the goal (Carver and Scheier 1990; Clore et al. 2001), and action toward the goal (Fishbach and Dhar 2006). In the present research, we focused specifically on the role of positive affect as feedback information allowing for adjustment in the activation level of adopted goals.

Current theorizing about the impact of positive affect as informational feedback in goal pursuit suggests two contradictory conclusions. Positive affect may signal that commitment to a goal should be maintained, indicating that the goal should remain activated. Conversely, the experience of positive affect may signal that sufficient progress has been made, indicating that the goal can be deactivated and that resources can be shifted to another goal system (Kruglanski et al. 2002). We propose that it is the presence (vs. absence) of a competing goal system that determines how feedback information derived from positive affect is interpreted. To test our predictions, two laboratory experiments 
were conducted examining the cognitive activation of a goal following a promise to complete it.

\section{Feedback information}

Researchers have investigated specific types of information that may serve as evidence as to whether sufficient progress toward a goal has been made, or whether continued commitment of resources to the pursuit of the goal is needed. To manipulate perceived commitment versus progress, Fishbach and Dhar (2006) asked participants to complete a questionnaire about their goal progress in which the comparison point was either very far from or very close to what the participant had already accomplished. When the comparison point was very far, suggesting low progress (in this case augmenting commitment), participants engaged in goal-consistent behavior. However, when the comparison point was very close, suggesting considerable goal progress, participants engaged in goal-inconsistent behavior. In other words, information implying that sufficient progress toward the goal has been made may lead to deactivation of the goal, whereas information suggesting that commitment to the goal should be maintained may lead to continued or increased goal activation.

\section{Positive affect}

One particularly important source of feedback in goal pursuit is positive affect. As argued below, in some conditions the experience of positive affect might lead to an increase in goal activation, whereas in other circumstances it might lead to a decrease in goal activation. We will consider each in turn.

Consider first the possibility that positive affect may lead to continued or increased activation of a goal. The experience of positive affect may signal that a goal is desirable, enjoyable, or attainable. This would be expected to increase the activation of the goal and to inspire increased goaldirected behavior. As stated by Clore et al. (2001, p. 43), "positive affective cues serve as an incentive, reward, or 'go' signal for using currently accessible information and pursuing currently accessible inclinations." Moreover, "whether experienced as self-confidence, as success, or as an indication that one's beliefs and expectations are valid, positive affect should serve as a go signal (or reward) ... for using whatever goal, strategy, information, or response is most accessible" (Clore et al. 2001, p. 43).

Indeed, recent evidence suggests that positive affect increases commitment to goals. For example, Custers and Aarts (2005) found that subliminal priming of goals led to greater goal commitment when positively-valenced adjectives were paired with the primes as compared to when neutral or negatively-valenced adjectives were paired with the primes. Similarly, Fishbach and Labroo (2007) found that induced positive affect prior to goal priming led to greater commitment to goals than when negative affect was induced. Therefore, they concluded that "positive mood serves as a booster, facilitating the adoption of accessible goals" (Fishbach and Labroo 2007, p. 169). This recent research provides empirical support for the theoretical claim that positive affect serves as a "go" signal.

Yet alternative considerations suggest that positive affect may prompt the deactivation of a goal. Carver and Scheier's (1990, 1998) cybernetic control model proposes that individuals monitor the rate of progress toward a goal in reference to a relevant criterion. When progress exceeds the criterion, positive affect is experienced. This may occur because the person exceeds the expected rate of progress or because the person passes some pertinent reference point. According to the cybernetic model, when such a threshold is reached, the actor deactivates the goal. This model suggests that when positive affect is experienced, it should lead to coasting on the focal goal in the form of diminished effort (Carver 2003).

Some evidence exists suggesting that positive affect can indeed lead to both the increased and decreased activation of a goal. When participants were given a performancebased stop-rule, ("continue working until you reach your objective"), then positive affect was related to less persistence on tasks, but when given an enjoyment-based stoprule was given ("continue working until the task is no longer enjoyable"), positive affect was associated with greater persistence on a task (Hirt et al. 1996).

Our analysis and the empirical evidence reviewed suggest that positive affect should sometimes lead to increased activation of an adopted goal, but should lead to the deactivation of an adopted goal under other circumstances. Positive affect should lead to increased goal activation when it signals commitment to the goal, whereas positive affect should lead to decreased goal activation when it signals that sufficient progress towards the goal has been made.

But, how does the actor determine whether the affect is signaling progress or commitment? Typically, information is used in a way that that fits the needs of the individual at a given moment, a phenomenon known as "motivated reasoning” (Dunning 1999; Kunda 1990, Kunda and Sinclair 1999; Kruglanski 1989, 1996b). This suggests that the individual's interpretation about progress or continued commitment might be affected by her or his momentary needs and interests. We therefore expect that positive affect will lead to decreased goal activation when the actor has a motivation to believe that sufficient progress has been made on the focal goal, but increased goal activation when the actor is motivated to believe that commitment to the focal goal should be maintained. In the context of goal pursuit, a central motivation may emanate from the competition among goals for a limited pool of available resources. 


\section{Competing goals}

Because the deactivation of the focal goal frees resources for alternative goal systems (Kruglanski et al. 2002), the presence of competing goals represents a specific condition that can be expected to have an impact on the motivation to infer progress versus commitment to a goal. When competing goals are present, the individual is motivated to infer progress on the current task because an alternative goal system requires resources. In the absence of competing goals, the primary processing motivation should be to perceive the focal goal as attainable and desirable, leading to increased goal activation.

Based on these considerations, we predict that the presence of competing goals will motivate the actor to use positive affect as information indicating that sufficient progress towards the focal goal has been made, leading to decreased goal activation. Conversely, the absence of competing goals should motivate the actor to use positive affect as information indicating that commitment to the goal should be maintained, leading to increased goal activation.

\section{The present research}

In our first experiment, we manipulated the presence versus absence of competing goals, with the expectation that in the absence of competing goals the primary processing motivation is to infer continued commitment to the focal goal whereas in the presence of competing goals the primary processing motivation is to infer progress on the focal goal. Because an inference of commitment should lead to an increase in goal activation and an inference of progress should lead to a decrease in goal activation, we predicted that when competing goals are absent, induced positive affect (vs. neutral affect) should lead to greater focal goal activation, whereas when competing goals are present, positive affect (vs. neutral affect) should lead to a lesser activation of the focal goal. Our second experiment was designed to conceptually replicate the findings from Experiment 1 using a measure of participants' behavioral intentions rather than the reaction time measure of goal activation used in the first experiment. If this pattern of results is found across the studies, it would suggest an important moderator determining when positive affect leads to the continued activation or deactivation of a goal.

\section{Experiment 1}

The predictions outlined above suggest that positive affect can lead to the deactivation of a goal under some conditions. However, theorists have generally assumed that the stronger the adoption of a goal, the more effort a person will exert towards the goal and the greater the likelihood that the goal will be pursued and attained (e.g., Carver and Scheier 1990; Locke and Latham 1990). Therefore, to appropriately test the hypothesis that participants deactivate the goal due to an inference of progress, we must be sure that participants firmly and genuinely intend to complete the goal. To accomplish this, participants were asked to generate goals ideographically to be sure that they had a genuine interest in pursuing the goals. In addition, participants wrote a promise to complete the goal to be sure of participants' adoption of the goal.

Participants first generated one interpersonal goal and thought about it for $2 \mathrm{~min}$. They then entered one word into the computer to represent this goal. To manipulate the presence versus absence of competing goals, participants listed goals that they wanted to attain later that day or goals that had already been completed. Participants then promised to complete their focal goal. Following this, participants were presented with pictures in order to induce positive or neutral affect. Finally, participants completed a lexical decision task in which the word representing their focal goal was included. The reaction time to that word served as the dependent measure of goal activation.

\section{Method}

Participants

Seventy-six undergraduate students at the University of Maryland (47 female, 29 male) participated in exchange for course credit. Participants were 18-28 years of age, with a mean age of 20 .

Materials and procedure

Participants completed all procedures on a desktop computer. First, to activate an interpersonal goal, they were asked to think about something they would like to do for another person. Participants were given the following instructions:

... think about something that you would like to do for someone close to you, such as your significant other, close friend, or close relative. It should not be too trivial such as responding to an email if you email each other regularly. Nor should it be too large such as making a marriage proposal. Please think about exactly what you would like to do and how you will do it for 2 minutes. 
Once 2 min had elapsed, the computer prompted participants to enter one word to "summarize or stand for the action" they thought about (see Shah and Kruglanski 2003). Participants entered a large variety of goals, such as "visit," "surprise," "gift," "dinner," and "shoes."

\section{Making the promise}

Participants were asked to write a pledge to complete the activity that they indicated they would like to do for someone else. They were instructed to start their written statement with "I promise..."

\section{Competing goals}

Immediately after thinking about the interpersonal goal, and before promising to complete the goal, the presence (vs. absence) of competing goals was manipulated by randomly assigning participants to one of two conditions. To activate competing goals, participants were asked to list three activities they "would like to accomplish today." In the control condition competing goals were not activated, and instead participants listed three activities they "had already accomplished today."

\section{Affect manipulation}

After promising, affect was induced by randomly assigning participants to one of two conditions (positive vs. neutral affect). In both conditions, participants were told they would be presented with a series of pictures prior to performing a word recognition task. Five pictures from the International Affective Picture System (IAPS; Lang et al. 2005) were presented to participants for $12 \mathrm{~s}$ each, totaling 1 min of exposure. In the positive affect condition, five pictures were presented that had been extensively pretested to arouse positive affect (e.g., a smiling baby). In the neutral affect condition, five pictures were presented that had been extensively pre-tested to be affectively neutral (e.g., a blue towel).

The pictures from the IAPS used in the positive mood condition (with mean valence on a 9-point scale as reported in the IAPS manual in parentheses) were images 1920 $(M=7.90), 2050(M=8.20), 2340 \quad(M=8.03), 5833$ $(M=8.22)$, and $7502(M=7.75)$. The pictures presented in the neutral mood condition were images $2102(M=$ 5.16), $5130(M=4.45), 7006(M=4.88), 7036(M=$ $4.88)$, and $7002(M=4.97)$. To test the efficacy of this manipulation using our procedure with University of Maryland undergraduates, we presented these sets of images to 50 students using the same procedure and instructions as in our two experiments. We then assessed participants' mood by asking them to rate on a 7-point scale how positive, good, and pleasant they were feeling at that moment $(\alpha=.96)$. Participants reported being in a more positive mood after viewing the positive pictures $(M=5.12)$ than after viewing the neutral pictures $(M=$ 4.52), $t(48)=2.04, p<.05$. Taken together with the extensive pre-testing conducted by Lang et al. (2005), this constitutes strong evidence that this affect induction had the intended effect on participants' mood.

\section{Goal activation}

Finally, participants completed a lexical decision task in which their goal-relevant word was embedded. The reaction time to this word served as a measure of the activation of its associated goal. Participants were instructed that the task required them to indicate as quickly and as accurately as possible whether a string of letters constituted a meaningful word or not. An X marked the location on the computer screen in which the word was to appear and was displayed for $2 \mathrm{~s}$, followed by the letter string. Participants pressed one key if the letter string represented a meaningful word and a different key if it did not. Participants responded to an equal number of each response type over the course of the trials. Specifically, participants were presented with the word that was entered to represent their interpersonal goal (ideographically), six non-words (e.g., pind), and five neutral words (e.g., table). The presentation order of the targets was randomly determined for each participant. Prior to completing the measurement trials, participants completed six practice trials to orient them to the nature of the task.

The trial of interest in this experiment was the one in which the word representing the interpersonal goal was displayed and responded to. The response latency for this word was used as a measure of goal activation (see Shah and Kruglanski 2003). Faster reaction times to the words indicated greater goal activation. Because participants generated the goal ideographically, it was only possible to use the self-generated word in the lexical decision task rather than multiple words that may relate to the goal. If this word had been presented multiple times, the first presentation may have influenced response latencies to the subsequent presentations. For this reason, the word representing each interpersonal goal was presented only once. The response latencies to the neutral words were also recorded, and the average of the response latencies across the six words served as a composite reflecting individual differences in responding to this task generally.

All response latencies were logarithmically transformed to lessen the influence of outliers (cf. Fazio 1990). Because the speed of participants' incorrect responses would have been difficult to interpret in terms of accessibility, only correct responses were used in data analysis (see Bargh 
et al. 1992). All participants responded correctly to the words representing their focal goal, therefore no participants were excluded for this reason.

\section{Results and discussion}

We conducted a 2 (competing goals: present vs. absent $) \times 2$ (affect: positive vs. neutral) between-subjects ANCOVA, with response latencies to neutral words entered as a covariate. The results found support for the predicted twoway interaction between the presence of competing goals and affect, $F(1,71)=7.50, p<.01$. To further test our hypotheses, we analyzed the simple effects. When competing goals were present, reaction times to the focal goal were significantly slower in the positive affect condition $(M=680 \mathrm{~ms}, \mathrm{SE}=31)$ than in the neutral affect condition $(M=595 \mathrm{~ms}, \mathrm{SE}=29), t(71)=2.11, p<.05$. When competing goals were absent, reaction times to the focal goal were significantly faster in the positive affect condition $(M=561 \mathrm{~ms}, \mathrm{SE}=32)$ than in the neutral affect condition $(M=627 \mathrm{~ms}, \mathrm{SE}=29), t(71)=2.02, p<.05$ (Fig. 1).

In addition to the results discussed above, we expected that experiencing positive affect after promising to complete the goal should lead to greater goal activation when competing goals were absent as compared to when competing goals were present. Confirming this prediction, reaction times to the focal goal after experiencing positive affect were slower in the competing goals condition $(M=680 \mathrm{~ms}, \mathrm{SE}=31)$ than when competing goals were not activated $(M=561 \mathrm{~ms}, \quad \mathrm{SE}=32), \quad t(71)=2.82$, $p<.001$. However, there was no effect of competing goals in the neutral affect condition, $t(71)=1.24$, $n s$.

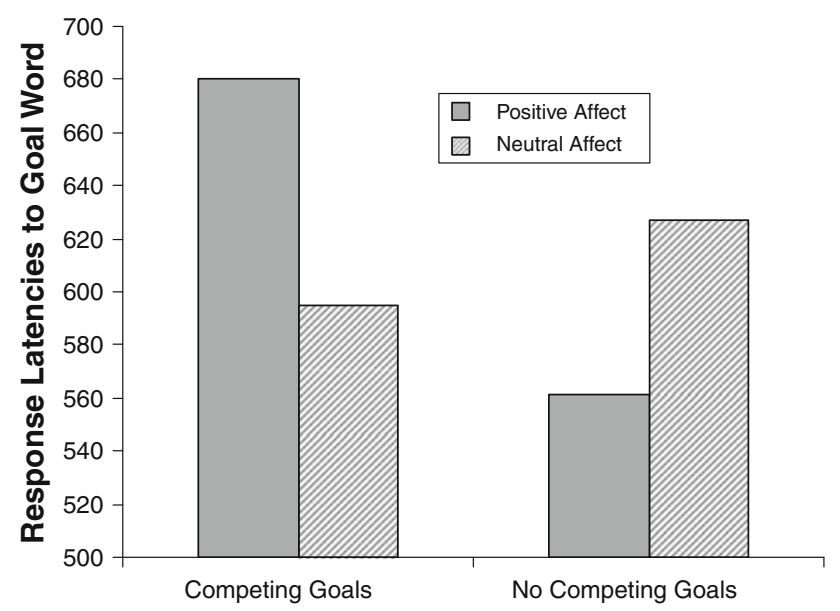

Fig. 1 The effect of affect and competing goals on the activation of the focal goal (Experiment 1)
The results from this experiment support our hypotheses. When competing goals were present at the time of promising, the activation of the focal goal was lower when positive affect was experienced as compared to when neutral affect was experienced. However, when competing goals were not present at the time of promising, the activation of the focal goal was greater in the positive affect condition than in the neutral affect condition. The data suggest that competing goals provide the motivation to shift resources away from the focal goal to the competing goals. This shift is possible when positive affect can serve as information indicating goal progress. When no competing goals are present, positive affect serves as information suggesting that the actor is on the right track towards achievement of the focal goal and should continue moving toward it because the focal goal is the sole concern. In support of the notion that positive affect serves the role of feedback information, the presence of competing goals only mattered when positive, but not neutral, affect was induced.

\section{Experiment 2}

Our second experiment was designed to conceptually replicate the findings from the first experiment using a measure of participants' behavioral intentions rather than a goal activation measure (determined from reaction times). Using a behavioral intentions measure allowed us to test whether positive affect is likely to have an impact beyond goal activation on subsequent goal-directed behavior. Additionally, in the control condition, in which competing goals were not present, participants listed three colors rather than three things they had already accomplished that day.

\section{Method \\ Participants}

Seventy-eight undergraduates at the University of Maryland (40 female, 38 male) participated in exchange for partial course credit. Participants were 18-29 years of age, with a mean age of 20 .

Procedure

The procedure for this study was identical to Experiment 1 except for the manipulation of competing goals and the measure of behavioral intentions rather than goal activation. Participants again generated an interpersonal goal and entered one word into the computer to represent this goal. 
Participants promised to complete the goal, and were presented with the same pictures pre-tested to elicit either positive or neutral affect.

\section{Competing goals}

Prior to promising to complete their focal goal, participants in the competing goals condition listed three things they would like to do later that day. Participants in the control condition listed three colors.

\section{Behavioral intentions}

Participants completed a measure of their behavioral intentions regarding the promised goal. Participants responded to two items, "I plan to complete the goal I wrote about" and "I intend to complete the goal I wrote about" on a 9-point Likert scale ranging from 1 (not at all) to 9 (very much). Because these items were highly correlated $(r=.94, p<.001)$, we averaged them to create a composite score.

\section{Results and discussion}

A 2 (affect: positive vs. neutral) $\times 2$ (competing goals: presence vs. absence) between-subjects ANOVA was conducted to test our hypothesis. We found a significant main effect of competing goals, $F(1,74)=5.58, p<.05$ indicating less strong behavioral intentions were held when competing goals were present $(M=7.73, \mathrm{SD}=.18)$ than when competing goals were absent $(M=8.32, \mathrm{SD}=.18)$. More importantly, we found the predicted two-way interaction between affect and competing goals, $F(1,74)=$ $10.23, p<.01$. As shown in Fig. 2, behavioral intentions regarding the focal goal were weaker in the positive affect condition $(M=7.30, \mathrm{SD}=.25)$ than in the neutral affect condition $(M=8.16, \mathrm{SD}=.26)$ when competing goals were present, $t(74)=2.39, p<.05$. In contrast, when competing goals were absent, behavioral intentions were stronger in the positive affect condition $(M=8.70$, $\mathrm{SD}=.25)$ than in the neutral affect condition $(M=7.95$, $\mathrm{SD}=.26), t(74)=2.10, p<.05$.

Additionally, we expected to conceptually replicate the finding from Experiment 1 in which competing goals had an impact in the positive affect condition, but not in the neutral affect condition. That is, when positive affect was experienced after promising to complete the goal, it should lead to stronger behavioral intentions when no competing goals had been activated as compared to when competing goals had been activated. However, in the neutral affect condition, the actor is devoid of information to make inferences regarding progress or commitment to the goal, which should eliminate

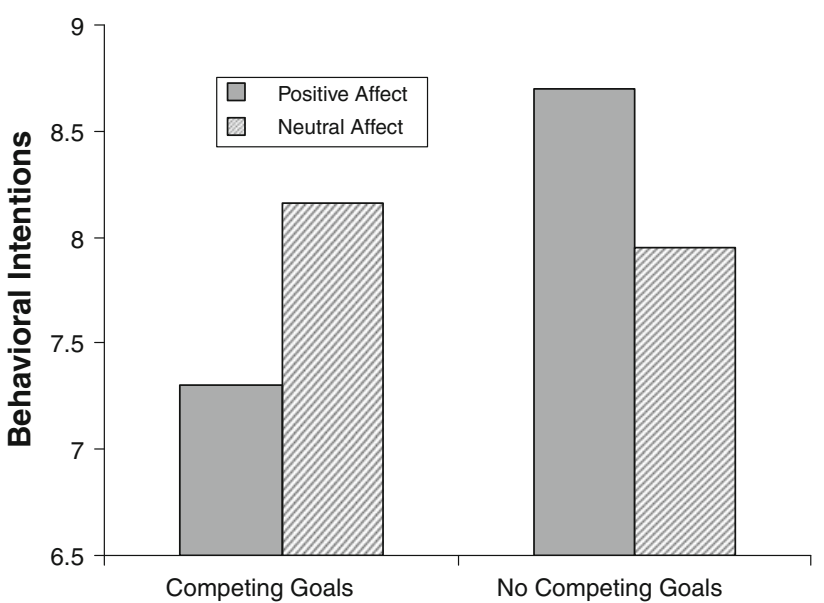

Fig. 2 The effect of affect and competing goals on behavioral intentions following a promise (Experiment 2)

any difference between these two conditions. Confirming this prediction, behavioral intentions after experiencing positive affect were lower in the competing goals condition $(M=7.30, \mathrm{SD}=.25)$ than when competing goals were not activated $(M=8.70, \mathrm{SD}=.25), t(74)=3.95, p<.001$. However, there was no effect of competing goals in the neutral affect condition, $t(74)=.58, n s$.

The results from Experiment 2 conceptually replicate the findings in Experiment 1. These results provide further evidence that the presence versus absence of competition for resources from alternative goals represents a critical moderator determining how positive affect influences goal activation. When competing goals are activated, positive (vs. neutral) affect led to decreased goal activation. When competing goals are not activated, positive (vs. neutral) affect led to increased goal activation.

\section{General discussion}

In two experiments, we tested the impact of positive affect as informational feedback in goal pursuit. In each study, we had participants promise to complete a goal. In Experiment 1 , we found that induced positive affect (vs. neutral affect) led to lesser activation of the focal goal when competing goals were present. However, induced positive affect (vs. neutral affect) led to greater activation of the focal goal when competing goals were absent. Experiment 2 replicated this pattern of results with behavioral intentions rather than a reaction time measure of goal activation serving as the dependent variable.

We found that when positive affect is experienced after a promise to complete a goal, it sometimes leads to a decrease in activation of the goal, but sometimes leads to an increased or maintained activation of the goal. We showed that when a competition for resources from 
alternative goals was present, positive affect, as compared to neutral affect, led to lesser activation of the focal goal. This competition presumably led to a motivation to infer progress on the focal goal so that the actor could shift resources to the competing goals. Positive affect, because it is often experienced when goals are attained, can serve as such feedback information. However, when no such competition from alternative goals was present, positive (vs. neutral) affect led to greater focal goal activation.

Our results point to the flexibility with which positive affect can be used as information to infer the current status of goal pursuit. That is, positive affect can serve as information to suggest both goal progress and goal commitment. Other types of information, such as the specific behaviors enacted, have also been shown to be interpreted in a similarly flexible manner (Fishbach and Dhar 2006). Previous research has focused on the cognitive interpretation of progress-related information, whereas our research examined the motivated use of such information. When the actor is motivated to infer progress because of the competition for resources from alternative goals, positive affect is more likely to lead to decreased goal activation. However, when the actor is motivated to infer commitment because the focal goal is the sole concern, positive affect is more likely to lead to increased goal activation. It seems that the motivated use of feedback information to infer progress on the focal goal is one strategy that people use to deal with the resources demands when multiple goals are active.

One limitation with the current experiments is that participants'goal-directed behavior was not measured. Instead, we measured the momentary activation of the goals and behavioral intentions. Yet, we have every reason to believe that the same pattern of findings would be observed if a behavioral measured were employed. This is because the link between goal activation and goal pursuit has been found to be quite robust. Theories of goal pursuit assume that goals will be pursued to the extent that they are activated (e.g., Bargh 1990; Förster et al. 2007; Kruglanski 1996a; Kruglanski et al. 2002). Experimental evidence for this claim comes from priming studies demonstrating that the priming of a goal (thereby increasing its' activation) causes increased goal-consistent behavior (e.g., Bargh et al. 2001; Chartrand and Bargh 1996). Not only is the resulting behavior consistent with the goal, but the goal activation had been shown to lead to goal commitment (Bargh et al. 2001), as shown through persistance in the face of obstacles and resumption of the goal following an interruption. The measurement of behavioral intentions in addition to the mere activation of the goal provides further evidence suggesting that the present framework would apply to the actual pursuit of the goal. Even so, future research could profitably explore the present framework using behavioral measures of goal pursuit.
Open Access This article is distributed under the terms of the Creative Commons Attribution Noncommercial License which permits any noncommercial use, distribution, and reproduction in any medium, provided the original author(s) and source are credited.

\section{References}

Atkinson, J. W., \& Raynor, J. O. (1978). Personality, motivation, and achievement. Oxford, England: Hemisphere.

Bargh, J. A. (1990). Auto-motives: Preconscious determinants of social interaction. In E. T. Higgins \& R. M. Sorrentino (Eds.), Handbook of motivation and cognition: Foundations of social behavior (pp. 93-130). New York: Guilford.

Bargh, J. A., Chaiken, S., Govender, R., \& Pratto, P. (1992). The generality of the automatic attitude activation effect. Journal of Personality and Social Psychology, 62, 893-912.

Bargh, J., Gollwitzer, P., Lee-Chai, A., Barndollar, K., \& Trötschel, R. (2001). The automated will: Nonconscious activation and pursuit of behavioral goals. Journal of Personality and Social Psychology, 81(6), 1014-1027.

Carver, C. (2003). Pleasure as a sign you can attend to something else: Placing positive feelings within a general model of affect. Cognition and Emotion, 17(2), 241-261.

Carver, C. S., \& Scheier, M. F. (1990). Origins and functions of positive and negative affect: A control-process view. Psychological Review, 97, 19-35.

Carver, C. S., \& Scheier, M. F. (1998). On the self-regulation of behavior. New York: Cambridge University Press.

Chartrand, T., \& Bargh, J. (1996). Automatic activation of impression formation and memorization goals: Nonconscious goal priming reproduces effects of explicit task instructions. Journal of Personality and Social Psychology, 71, 464-478.

Clore, G. L., Wyer, R. S., Dienes, B., Gasper, K., Gohm, C., \& Isbell, L. (2001). Affective feelings as feedback: Some cognitive consequences. In L. L. Martin \& G. L. Clore (Eds.), Theories of mood and emotion: A user's guidebook (pp. 27-62). Mahwah: Lawrence Erlbaum Associates Publishers.

Custers, R., \& Aarts, H. (2005). Positive affect as implicit motivator: On the nonconscious operation of behavioral goals. Journal of Personality and Social Psychology, 89, 129-142.

Dunning, D. (1999). A new look: Motivated social cognition and the schematic representation of social concepts. Psychological Inquiry, 10, 1-11.

Fazio, R. H. (1990). A practical guide to the use of response latency in social psychological research. In C. Hendrick \& M. S. Clark (Eds.), Research methods in personality and social psychology, review of personality and social psychology (Vol. 11, pp. 74-97). Newberry Park: Sage.

Feather, N. T. (1990). Bridging the gap between values and actions: Recent applications of the expectancy-value model. In E. T. Higgins \& R. M. Sorrentino (Eds.), Handbook of motivation and cognition: Foundations of social behavior (Vol. 2, pp. 151-192). New York: Guilford Press.

Fishbach, A., \& Dhar, R. (2006). Goals as excuses or as guides: The liberating effect of perceived goal progress on choice. Journal of Consumer Research, 32, 370-377.

Fishbach, A., \& Labroo, A. A. (2007). Be better or be merry: How mood affects self-control. Journal of Personality and Social Psychology, 93, 158-173.

Förster, J., Liberman, N., \& Friedman, R. (2007). Seven principles of goal activation: A systematic approach to distinguishing goal priming from priming of non-goal constructs. Personality and Social Psychology Review, 11, 211-233. 
Forster, J., Liberman, N., \& Higgins, E. T. (2005). Accessibility from active and fulfilled goals. Journal of Experimental Social Psychology, 41, 220-239.

Gollwitzer, P. M. (1999). Implementation intentions: Strong effects of simple plans. American Psychologist, 54, 493-503.

Hirt, E., Melton, R., McDonald, H., \& Harackiewicz, J. (1996). Processing goals, task interest, and the mood-performance relationship: A mediational analysis. Journal of Personality and Social Psychology, 71(2), 245-261.

Kruglanski, A. W. (1989). Lay epistemics and human knowledge: Cognitive and motivational bases. New York: Plenum Press.

Kruglanski, A. W. (1996a). Goals as knowledge structures. In P. M. Gollwitzer \& J. A. Bargh (Eds.), The psychology of action: Linking cognition and motivation to behavior (pp. 599-618). New York: Guilford Press.

Kruglanski, A. W. (1996b). Motivated social cognition: Principles of the interface. In E. T. Higgins \& A. W. Kruglanski (Eds.), Social psychology: Handbook of basic principles (pp. 493-520). New York: Guilford Press.

Kruglanski, A. W., Shah, J. Y., Fishbach, A., Friedman, R., Chun, W. Y., \& Sleeth-Keppler, D. (2002). A theory of goal systems. In: M. P. Zanna (Ed.), Advances in experimental social psychology, 34 (pp. 331-378).

Kunda, Z. (1990). The case for motivated reasoning. Psychological Bulletin, 108, 480-498.
Kunda, Z., \& Sinclair, L. (1999). Motivated reasoning with stereotypes: Activation, application, and inhibition. Psychological Inquiry, 10, 12-22.

Lang, P. J., Bradley, M. M., \& Cuthbert, B. N. (2005). International affective picture system (IAPS): Affective ratings of pictures and instruction manual. Technical Report A-6. Gainesville: University of Florida.

Locke, E. A., \& Latham, G. P. (1990). A theory of goal setting and task performance. Upper Saddle River: Prentice-Hall.

Marsh, R. L., Hicks, J. L., \& Bink, M. L. (1998). Activation of completed, uncompleted and partially completed intentions. Journal of Experimental Psychology. Learning, Memory, and Cognition, 24, 350-361.

Oettingen, G., \& Mayer, D. (2002). The motivating function of thinking about the future: Expectations versus fantasies. Journal of Personality and Social Psychology, 83, 1198-1212.

Shah, J. Y., \& Kruglanski, A. W. (2003). When opportunity knocks: Bottom-up priming of goals by means and its effects on selfregulation. Journal of Personality and Social Psychology, 84, $1109-1122$.

Zeigarnik, B. (1927). Über das Behalten von erledigten und underledigten Handlungen. Psychologische Forschung, 9, 1-85. 